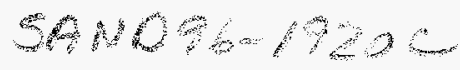

\title{
Self-Aligned Selective Emitter Plasma-Etchback and Passivation Process for Screen-Printed Silicon Solar Cells
}

\author{
D. S. Ruby ${ }^{1}$, C. B. Fleddermann ${ }^{2}$, M. Roy ${ }^{3}$ and S. Narayanan ${ }^{3}$ \\ ${ }^{1}$ Sandia National Laboratories, Albuquerque, NM 87185-0752 \\ ${ }^{2}$ University of New Mexico, Albuquerque, NM 87131 \\ ${ }^{3}$ Solarex (a business unit of Amoco/Enron Solar), Frederick, MD 21701
}

RECEIVED

\section{Abstract}

Plasma-enhanced chemical vapor deposition (PECVD) is now widely recognized as a potentially cost-effective, performance-enhancing technique that can provide surface passivation and produce an effective antireflection coating layer at the same time. In order to gain the full benefit from improved emitter surface passivation on cell performance, it is necessary to tailor the emitter doping profile so that the emitter is lightly doped between the gridlines, but heavily doped under them. This is especially true for screen-printed gridlines, which require very heavy doping beneath them for acceptably low contact resistance. This selectively patterned emitter doping profile has historically been obtained by using expensive photolithographic or screen-printed alignment techniques and multiple high-temperature diffusion steps. We have built on a self-aligned emitter etchback technique first described by Spectrolab. In addition to the gridline-masked, plasma-etchback of the emitter they developed, we have included PECVD-nitride deposition because the low-recombination emitter produced by the etchback requires good surface passivation for improved cell performance. The nitride also provides a good antireflection coating and can be combined with plasma-hydrogenation treatments for bulk defect passivation.

We studied whether plasma-etching techniques can use standard screen-printed gridlines as etch masks to form self-aligned, patterned-emitter profiles on multicrystalline (mcSi) cells from Solarex Corp. We conducted an investigation of plasma deposition and etching processes on full-size mc-Si cells processed in commercial production lines, so that any improvements obtained would be immediately relevant to the PV industry.

This investigation determined that reactive ion etching (RIE) is compatible with using standard, commercial, screen-printed gridlines as etch masks to form self-aligned, selectivelydoped emitter profiles. This process results in reduced gridline contact resistance when followed by PECVD treatments, an undamaged emitter surface easily passivated by plasmanitride, and a less heavily doped emitter between gridlines for reduced emitter recombination. This allows for heavier doping beneath the gridlines for even lower contact resistance, reduced contact recombination, and better bulk defect gettering. Our initial results found a statistically significant improvement of about half an absolute percentage point in cell efficiency when the self-aligned emitter etchback was combined with the PECVD-nitride surface passivation treatment. Additional improvement is expected when the successful bulk passivation treatment is also added to the process.

\section{Introduction}

The use of plasma-enhanced chemical vapor deposition (PECVD) as a lowtemperature surface passivation technique for silicon solar cells is a topic of increasing

This work was supported by the U.S. Department of Energy under contract DE-AC0494AL85000. 


\section{DISCLAIMER}

Portions of this document may be illegible in electronic image products. Images are produced from the best available original document. 


\section{DISCLAIMER}

This report was prepared as an account of work sponsored by an agency of the United States Government. Neither the United States Government nor any agency thereof, nor any of their employees, makes any warranty, express or implied, or assumes any legal liability or responsibility for the accuracy, completeness, or usefulness of any information, apparatus, product, or process disclosed, or represents that its use would not infringe privately owned rights. Reference herein to any specific commercial product, process, or service by trade name, trademark, manufacturer, or otherwise does not necessarily constitute or imply its endorsement, recommendation, or favoring by the United States Government or any agency thereof. The views and opinions of authors expressed herein do not necessarily state or reflect those of the United States Government or any agency thereof. 
importance. PECVD is now widely recognized as a potentially cost-effective, performanceenhancing technique that can provide surface passivation and produce an effective antireflection coating layer at the same time [1]. For some solar-grade silicon materials, it has been observed that the PECVD process results in the improvement of bulk minority-carrier diffusion lengths as well, presumably due to bulk defect passivation [2].

In order to gain the full benefit from improved emitter surface passivation on cell performance, it is necessary to tailor the emitter doping profile so that the emitter is lightly doped between the gridlines, but heavily doped under them [3]. This is especially true for screen-printed gridlines, which require very heavy doping beneath them for acceptably low contact resistance. This selectively patterned emitter doping profile has historically been obtained by using expensive photolithographic or screen-printed alignment techniques and multiple high-temperature diffusion steps $[3,4]$.

We have attempted to build on a self-aligned emitter etchback technique first described by Spectrolab [5]. In addition to the gridline-masked, plasma-etchback of the emitter they developed, we have included plasma-hydrogenation treatments for bulk defect passivation followed by PECVD-nitride deposition for surface passivation and antireflection coating.

\section{Experimental Procedure}

The plasma-nitride depositions were performed using a modified Pacific Western Coyote PECVD reactor. This is a commercial, RF parallel-plate reactor operating at 13.56 $\mathrm{MHz}$ with large batch-size and high-throughput potential. Reaction gases for nitride deposition were a $3 \%$ mixture of silane in nitrogen and pure ammonia.

These cells were made using Solarex cast multicrystalline silicon and received Solarex's standard production line processing through the printing and firing of the gridlines. Then, the cells underwent reactive ion etching (RIE) for 3 minutes to increase the sheet resistance of the emitters to $80-100 \mathrm{ohms} / \mathrm{square}$. They were plasma-etched in a Technics PE II-A reactor using pure $\mathrm{SF}_{6}$ at a power of $10 \mathrm{~W}$ and a pressure of $100 \mathrm{mTorr}$. Then, the cells received either an ammonia-plasma hydrogenation (H-passivation) treatment or a silicon-nitride deposition (PECVD-nitride), both found to be effective for bulk and surface passivation in String Ribbon $^{\mathrm{TM}}$ mc-Si [2]. They were then returned to the Solarex production-line for final cell processing.

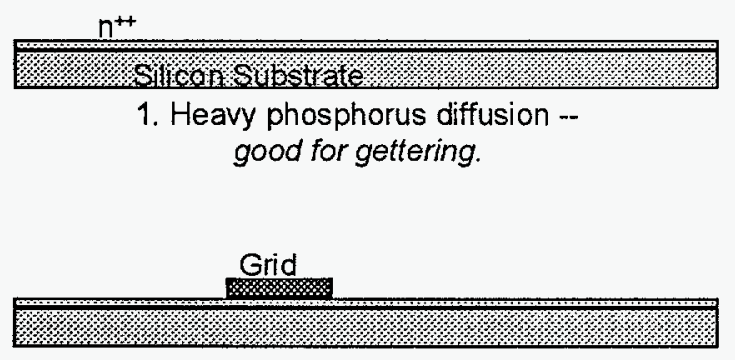

2. Apply front grid -standard commercial metallization.

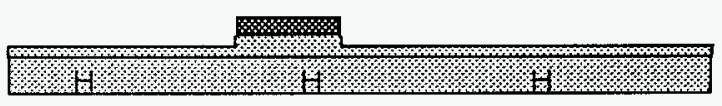

3. Plasma etch emitter and use grid to mask etch beneath grid -- self-aligned. Hydrogen-plasma for bulk passivation.

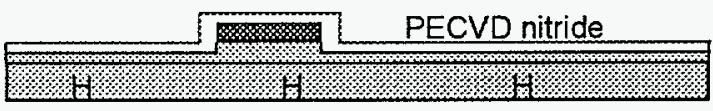

4. PECVD film for surface passivation and ARC -same reactor for low cost.

Figure 1. Process sequence for self-aligned emitter etchback. The emitter etchback can be performed after the hydrogen-plasma treatment to remove surface damage. However, in this work, the plasma-etching was done first. 


\section{Results}

Table 1. Four processing sequences were applied to twelve $102.6-\mathrm{cm}^{2}$ Solarex mc-Si cells using matched material from the same ingot and in most cases with the same grain structure.

\begin{tabular}{|c|c|c|c|c|}
\hline Eff. $(\%)$ & $\mathrm{I}_{\mathrm{SC}}(\mathrm{A})$ & $\mathrm{V}_{\mathrm{OC}}(\mathrm{mV})$ & $\mathrm{FF}(\%)$ & $\mathrm{R}_{\mathrm{S}}(\mathrm{m} \Omega)$ \\
\hline \multicolumn{5}{|c|}{ Group 1. Control Cells: No emitter etchback, $\mathrm{TiO}_{2} \mathrm{ARC}$} \\
\hline $12.6 \pm 0.1$ & $2.91 \pm .02$ & $586 \pm 1$ & $75.5 \pm 0.7$ & $9.2 \pm 0.5$ \\
\hline \multicolumn{5}{|c|}{ Group 2. Plasma Etchback, $\mathrm{TiO}_{2} \mathrm{ARC}$} \\
\hline $12.2 \pm 0.1$ & $2.93 \pm .02$ & $580 \pm 1$ & $73.4 \pm 0.4$ & $15.0 \pm 1.0$ \\
\hline \multicolumn{5}{|c|}{ Group 3. Plasma Etchback, $\mathrm{H}$-passivation, $\mathrm{TiO}_{2} \mathrm{ARC}$} \\
\hline $12.8 \pm 0.3$ & $2.97 \pm .02$ & $585 \pm 1$ & $75.4 \pm 1.5$ & $10.7 \pm 0.5$ \\
\hline \multicolumn{5}{|c|}{ Group 4. Plasma Etchback, PECVD-nitride ARC, FGA } \\
\hline $13.0 \pm 0.1$ & $3.00 \pm .01$ & $587 \pm 1$ & $75.3 \pm 0.2$ & $10.7 \pm 0.5$ \\
\hline
\end{tabular}

The cells from Group 2 suffered an efficiency loss due primarily to loss of $\mathrm{V}_{\mathrm{OC}}$, as expected, since the etched-back emitter is now transparent to minority carriers, which now recombine at the unpassivated front surface. An additional loss in FF is due to the increase in series resistance because of the extra sheet resistance of the etched-back emitter. In an optimized sequence, the cells would have more closely-spaced gridlines to compensate for this. In addition, an extra-heavy emitter doping could be performed, possibly resulting in additional gettering of bulk impurities, which could then be etched away. Also, heavier doping under the gridlines would better isolate them and reduce contact recombination. Finally, the heavier doping would also reduce the contact resistance that often limits screen-printed cell performance. The lack of current loss in these cells indicates that any increase in surface recombination is compensated for by reduced emitter recombination in the now lightly doped emitter.

The Group 3 cells have regained most of the $V_{O C}$ loss, probably due to the compensating effect of reduced bulk recombination from the hydrogenation treatment. Interestingly, this is accompanied by a reduction of the series resistance, which is in agreement with observations by Wenham et al., who attributed this to a decrease in the contact resistance of the screen-printed gridlines [7]. This, in combination with the benefits of heavier emitter doping mentioned above, would address many of the shortfalls that have been ascribed to the screen-printing process.

The cells from Group 4 have totally regained their initial $V_{O C}$ values and show a significant $3 \%$ gain in $\mathrm{I}_{\mathrm{SC}}$ now that the surface of the transparent emitter is passivated by the nitride film. The effect of the plasma-nitride deposition on reducing the gridline contact resistance is still apparent, resulting in an overall average increase in efficiency of almost half an absolute efficiency point. Even better results are expected when the nitride passivation is combined with bulk hydrogenation and the benefits of heavy emitter doping.

Internal quantum efficiency curves of typical cells from Groups 1, 3, and 4 are shown in Figure 2. LBIC scans showed that the cells from Group 2 did not have the same grain structure as the others, and so it was not possible to find the same "median" grain from cells of Group 2 on which to measure the IQE. 


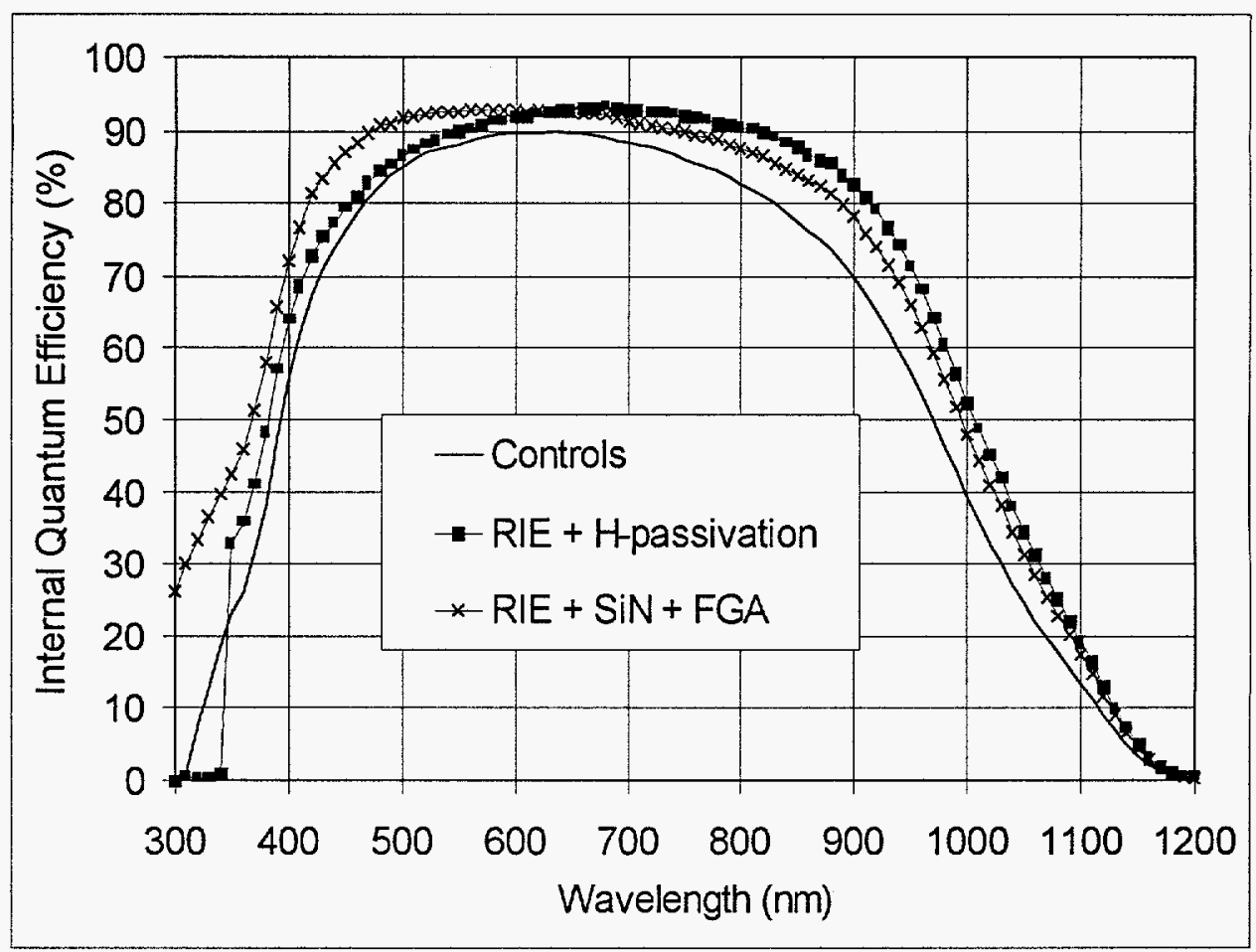

Figure 2. IQE curves of three Solarex cells representative of Groups 1, 3, and 4 described in Table 1.

The IQE curves show that while both plasma treatments increased the red-response relative to the control cell, the $\mathrm{NH}_{3}$-hydrogenation treatment had the biggest effect. It is also clear that the nitride-ARC resulted in the best blue response due to its better passivation of the emitter surface. In fact, the IQE(400-nm) value (73\%) is almost as high as that obtained previously on this material (78\%) using a nitride coating optimized for low surface recombination [6]. This shows that the RIE process may not have damaged the emitter surface significantly, if at all.

\section{Conclusions}

This investigation determined that RIE is compatible with using standard, commercial, screen-printed gridlines as etch masks to form self-aligned, selectively-doped emitter profiles. This process results in reduced gridline contact resistance, an undamaged emitter surface easily passivated by plasma-nitride, and a less heavily doped emitter between gridlines for reduced emitter recombination. It allows for heavier doping beneath the gridlines for even lower contact resistance, reduced contact recombination, and better bulk defect gettering. Future work in this area will incorporate the heavier emitter doping as well as performing the bulk hydrogenation before the RIE step so that surface damage from the bulk passivation step can be removed or reduced. This will be compared with the use of a protective nitride film before hydrogenation. Finally, all three plasma processes, the bulk passivation, emitter etchback, and nitride surface passivation, will be combined for the synergistic additive effect of their benefits. 


\section{Acknowledgements}

The authors would like to thank J. M. Gee for initially suggesting the self-aligned emitter etchback concept, and W. K. Schubert for his help in this area. We are also grateful to the processing staff at Sandia's PDFL and the Solarex production line for the cell processing. Many thanks also go to L. Irwin for the cell measurements.

\section{References}

[1] Z. Chen, P. Sana, J. Salami, and A. Rohatgi, "A Novel and Effective PECVD SiO2/SiN Antireflection Coating for Si Solar Cells," IEEE Trans. Elect. Dev., 40, June 1993, pp. 11611165 .

[2] D.S. Ruby, W.L. Wilbanks, C.B. Fleddermann, and J.I. Hanoka, "The Effect of HydrogenPlasma and PECVD-Nitride Deposition on Bulk and Surface Passivation in String-Ribbon Silicon Solar Cells," Proc. 13th EPSEC, October 1995, pp. 1412-1414.

[3] A. Blakers et al., "22.8\%-Efficient Silicon Solar Cell," Appl. Phys. Lett. 55, 1989, pp. 1363-1395.

[4] J. Coppye et al., "Non-Conventional Emitters for Polycrystalline Silicon Solar Cells," Proc. $10^{\text {th }}$ EPSEC, April 1991, pp. 657-660.

[5] N. Mardesich, "Solar Cell Efficiency Enhancement by Junction Etching and Conductive AR Coating Processes," Proc. $15^{\text {th }}$ PVSC, May 1981, pp. 446-449.

[6] D.S. Ruby, W.L. Wilbanks, and C.B. Fleddermann, "A Statistical Analysis of the Effect of PECVD Deposition Parameters on Surface and Bulk Recombination in Silicon Solar Cells," Proc. $I^{s t}$ WCPEC, Dec. 1994, pp. 1335-1338.

[7] S.R. Wenham, M.R. Willison, S. Narayanan, and M.A. Green, "Efficiency Improvement in Screen-Printed Polycrystalline Silicon Solar Cells by Plasma Treatments," Proc. $18^{\text {th }}$ PVSC, Oct. 1985, pp. 1008-1013.

\section{DISCLAIMER}

account of work sponsored by an agency of the United States This report was prepared as an accotes Government nor any agency thereof, nor any of their This reither the United States Coremplied, or assumes any legal liability or product, or employees, makes any warranty, express or implefs of any information, apparatus, preferer bility for the accuracy, completeness, or use would not infringe privately owne name, trademark, process disclosed, or represents that its use wuct, process, or service by trade namely its endorsement, recomprocess disclosed, or rpecific commercial product, penstitute or imply its enderens ence herein to any specier does not necessarily conernment or any agency therect those of the manufacturer, or otherwise doe United States Govern mendation, or favoring buthors expressed herein do and opinions of authors States Government or 


\title{
Self-Aligned Selective Emitter Plasma-Etchback and Passivation Process for Screen-Printed Silicon Solar Cells
}

\author{
D. S. Ruby ${ }^{1}$, C. B. Fleddermann ${ }^{2}$, M. Roy ${ }^{3}$ and S. Narayanan ${ }^{3}$ \\ ${ }^{1}$ Sandia National Laboratories, Albuquerque, NM 87185-0752 \\ ${ }^{2}$ University of New Mexico, Albuquerque, NM 87131 \\ ${ }^{3}$ Solarex (a business unit of Amoco/Enron Solar), Frederick, MD 21701
}

\begin{abstract}
Plasma-enhanced chemical vapor deposition (PECVD) is now widely recognized as a potentially cost-effective, performance-enhancing technique that can provide surface passivation and produce an effective antireflection coating layer at the same time. In order to gain the full benefit from improved emitter surface passivation on cell performance, it is necessary to tailor the emitter doping profile so that the emitter is lightly doped between the gridlines, but heavily doped under them. This is especially true for screen-printed gridlines, which require very heavy doping beneath them for acceptably low contact resistance. This selectively patterned emitter doping profile has historically been obtained by using expensive photolithographic or screen-printed alignment techniques and multiple high-temperature diffusion steps. We have built on a self-aligned emitter etchback technique first described by Spectrolab. In addition to the gridline-masked, plasma-etchback of the emitter they developed, we have included PECVD-nitride deposition because the low-recombination emitter produced by the etchback requires good surface passivation for improved cell performance. The nitride also provides a good antireflection coating and can be combined with plasma-hydrogenation treatments for bulk defect passivation.

We studied whether plasma-etching techniques can use standard screen-printed gridlines as etch masks to form self-aligned, patterned-emitter profiles on multicrystalline (mcSi) cells from Solarex Corp. We conducted an investigation of plasma deposition and etching processes on full-size mc-Si cells processed in commercial production lines, so that any improvements obtained would be immediately relevant to the PV industry.

This investigation determined that reactive ion etching (RIE) is compatible with using standard, commercial, screen-printed gridlines as etch masks to form self-aligned, selectivelydoped emitter profiles. This process results in reduced gridline contact resistance when followed by PECVD treatments, an undamaged emitter surface easily passivated by plasmanitride, and a less heavily doped emitter between gridlines for reduced emitter recombination. This allows for heavier doping beneath the gridlines for even lower contact resistance, reduced contact recombination, and better bulk defect gettering. Our initial results found a statistically significant improvement of about half an absolute percentage point in cell efficiency when the self-aligned emitter etchback was combined with the PECVD-nitride surface passivation treatment. Additional improvement is expected when the successful bulk passivation treatment is also added to the process.

\section{Introduction}

The use of plasma-enhanced chemical vapor deposition (PECVD) as a lowtemperature surface passivation technique for silicon solar cells is a topic of increasing
\end{abstract}

This work was supported by the U.S. Department of Energy under contract DE-AC0494AL85000. 
importance. PECVD is now widely recognized as a potentially cost-effective, performanceenhancing technique that can provide surface passivation and produce an effective antireflection coating layer at the same time [1]. For some solar-grade silicon materials, it has been observed that the PECVD process results in the improvement of bulk minority-carrier diffusion lengths as well, presumably due to bulk defect passivation [2].

In order to gain the full benefit from improved emitter surface passivation on cell performance, it is necessary to tailor the emitter doping profile so that the emitter is lightly doped between the gridlines, but heavily doped under them [3]. This is especially true for screen-printed gridlines, which require very heavy doping beneath them for acceptably low contact resistance. This selectively patterned emitter doping profile has historically been obtained by using expensive photolithographic or screen-printed alignment techniques and multiple high-temperature diffusion steps $[3,4]$.

We have attempted to build on a self-aligned emitter etchback technique first described by Spectrolab [5]. In addition to the gridline-masked, plasma-etchback of the emitter they developed, we have included plasma-hydrogenation treatments for bulk defect passivation followed by PECVD-nitride deposition for surface passivation and antireflection coating.

\section{Experimental Procedure}

The plasma-nitride depositions were performed using a modified Pacific Western Coyote PECVD reactor. This is a commercial, RF parallel-plate reactor operating at 13.56 $\mathrm{MHz}$ with large batch-size and high-throughput potential. Reaction gases for nitride deposition were a $3 \%$ mixture of silane in nitrogen and pure ammonia.

These cells were made using Solarex cast multicrystalline silicon and received Solarex's standard production line processing through the printing and firing of the gridlines. Then, the cells underwent reactive ion etching (RIE) for 3 minutes to increase the sheet resistance of the emitters to 80-100 ohms/square. They were plasma-etched in a Technics PE II-A reactor using pure $\mathrm{SF}_{6}$ at a power of $10 \mathrm{~W}$ and a pressure of $100 \mathrm{mT}$ Torr. Then, the cells received either an ammonia-plasma hydrogenation (H-passivation) treatment or a silicon-nitride deposition (PECVD-nitride), both found to be effective for bulk and surface passivation in String Ribbon $^{\mathrm{TM}}$ mc-Si [2]. They were then returned to the Solarex production-line for final cell processing.

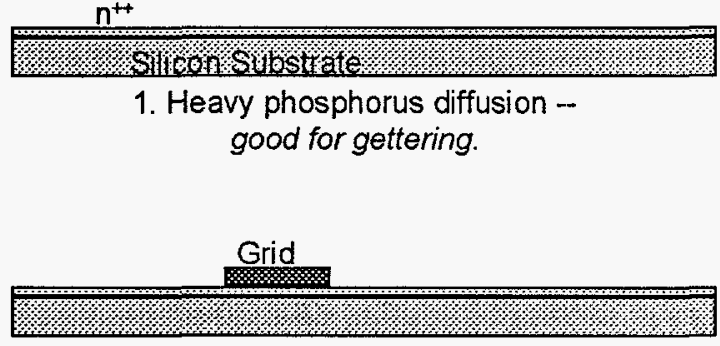

2. Apply front grid -.. standard commercial metallization.

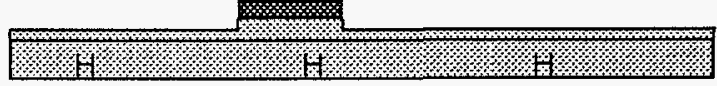

3. Plasma etch emitter and use grid to mask etch beneath grid -- self -aligned. Hydrogen-plasma for bulk passivation.

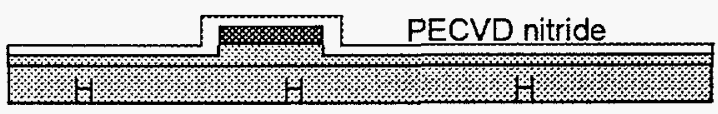

4. PECVD film for surface passivation and ARC same reactor for low cost.

Figure 1. Process sequence for self-aligned emitter etchback. The emitter etchback can be performed after the hydrogen-plasma treatment to remove surface damage. However, in this work, the plasma-etching was done first. 


\section{Results}

Table 1. Four processing sequences were applied to twelve $102.6-\mathrm{cm}^{2}$ Solarex mc-Si cells using matched material from the same ingot and in most cases with the same grain structure.

\begin{tabular}{|c|c|c|c|c|}
\hline Eff. (\%) & $I_{S C}(A)$ & $\mathrm{V}_{\mathrm{OC}}(\mathrm{mV})$ & FF (\%) & $\mathrm{R}_{\mathrm{S}}(\mathrm{m} \Omega)$ \\
\hline \multicolumn{5}{|c|}{ Group 1. Control Cells: No emitter etchback, $\mathrm{TiO}_{2}$ ARC } \\
\hline $12.6 \pm 0.1$ & $2.91 \pm .02$ & $586 \pm 1$ & $75.5 \pm 0.7$ & $9.2 \pm 0.5$ \\
\hline \multicolumn{5}{|c|}{ Group 2. Plasma Etchback, $\mathrm{TiO}_{2}$ ARC } \\
\hline $12.2 \pm 0.1$ & $2.93 \pm .02$ & $580 \pm 1$ & $73.4 \pm 0.4$ & $15.0 \pm 1.0$ \\
\hline \multicolumn{5}{|c|}{ Group 3. Plasma Etchback, H-passivation, $\mathrm{TiO}_{2} \mathrm{ARC}$} \\
\hline $12.8 \pm 0.3$ & $2.97 \pm .02$ & $585 \pm 1$ & $75.4 \pm 1.5$ & $10.7 \pm 0.5$ \\
\hline \multicolumn{5}{|c|}{ Group 4. Plasma Etchback, PECVD-nitride ARC, FGA } \\
\hline $13.0 \pm 0.1$ & $3.00 \pm .01$ & $587 \pm 1$ & $75.3 \pm 0.2$ & $10.7 \pm 0.5$ \\
\hline
\end{tabular}

The cells from Group 2 suffered an efficiency loss due primarily to loss of $V_{O C}$, as expected, since the etched-back emitter is now transparent to minority carriers, which now recombine at the unpassivated front surface. An additional loss in FF is due to the increase in series resistance because of the extra sheet resistance of the etched-back emitter. In an optimized sequence, the cells would have more closely-spaced gridlines to compensate for this. In addition, an extra-heavy emitter doping could be performed, possibly resulting in additional gettering of bulk impurities, which could then be etched away. Also, heavier doping under the gridlines would better isolate them and reduce contact recombination. Finally, the heavier doping would also reduce the contact resistance that often limits screen-printed cell performance. The lack of current loss in these cells indicates that any increase in surface recombination is compensated for by reduced emitter recombination in the now lightly doped emitter.

The Group 3 cells have regained most of the $V_{O C}$ loss, probably due to the compensating effect of reduced bulk recombination from the hydrogenation treatment. Interestingly, this is accompanied by a reduction of the series resistance, which is in agreement with observations by Wenham et al., who attributed this to a decrease in the contact resistance of the screen-printed gridlines [7]. This, in combination with the benefits of heavier emitter doping mentioned above, would address many of the shortfalls that have been ascribed to the screen-printing process.

The cells from Group 4 have totally regained their initial $V_{O C}$ values and show a significant $3 \%$ gain in $\mathrm{I}_{\mathrm{SC}}$ now that the surface of the transparent emitter is passivated by the nitride film. The effect of the plasma-nitride deposition on reducing the gridline contact resistance is still apparent, resulting in an overall average increase in efficiency of almost half an absolute efficiency point. Even better results are expected when the nitride passivation is combined with bulk hydrogenation and the benefits of heavy emitter doping.

Internal quantum efficiency curves of typical cells from Groups 1, 3, and 4 are shown in Figure 2. LBIC scans showed that the cells from Group 2 did not have the same grain structure as the others, and so it was not possible to find the same "median" grain from cells of Group 2 on which to measure the IQE. 


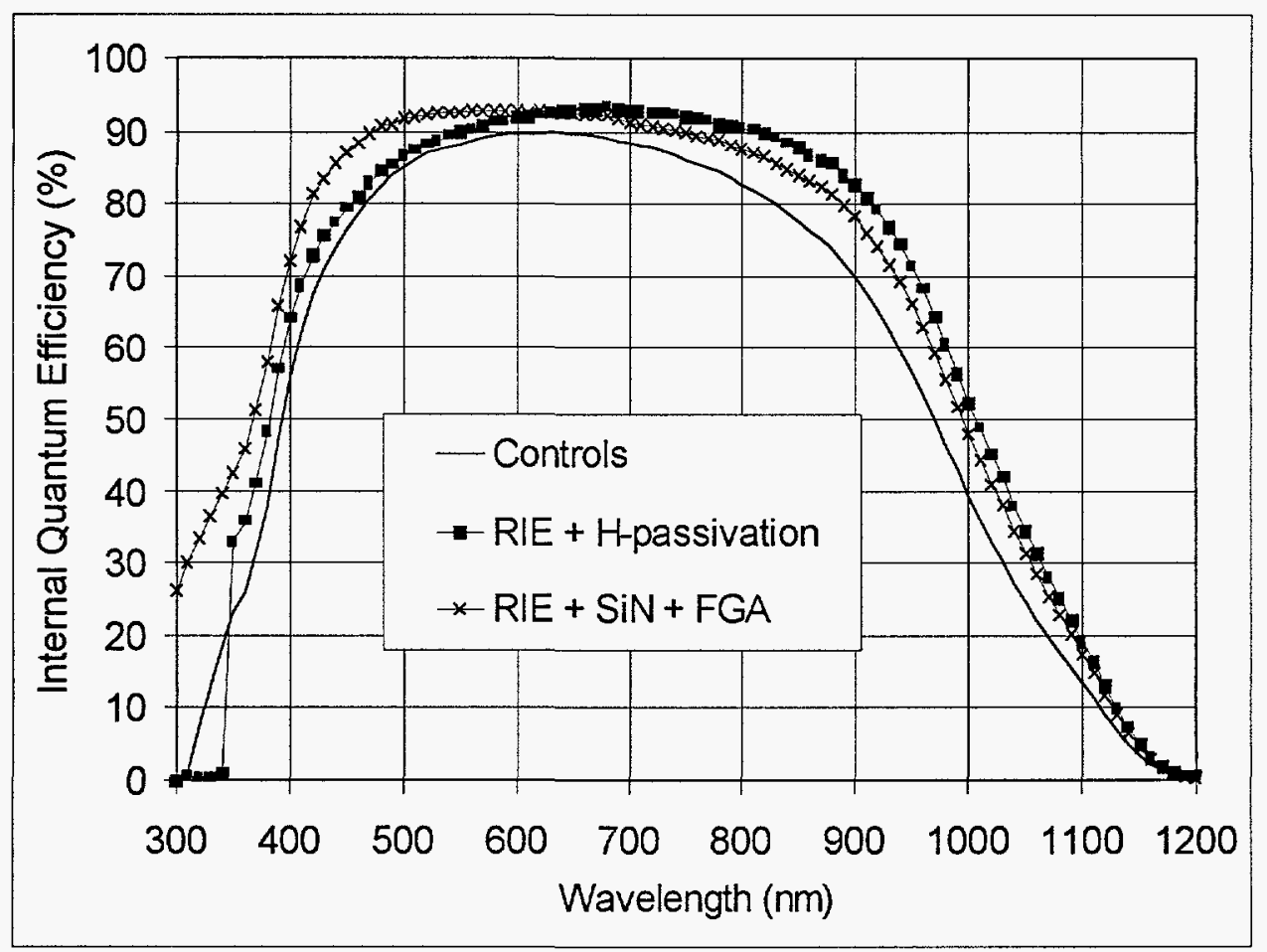

Figure 2. IQE curves of three Solarex cells representative of Groups 1, 3, and 4 described in Table 1.

The IQE curves show that while both plasma treatments increased the red-response relative to the control cell, the $\mathrm{NH}_{3}$-hydrogenation treatment had the biggest effect. It is also clear that the nitride-ARC resulted in the best blue response due to its better passivation of the emitter surface. In fact, the IQE(400-nm) value (73\%) is almost as high as that obtained previously on this material (78\%) using a nitride coating optimized for low surface recombination [6]. This shows that the RIE process may not have damaged the emitter surface significantly, if at all.

\section{Conclusions}

This investigation determined that RIE is compatible with using standard, commercial, screen-printed gridlines as etch masks to form self-aligned, selectively-doped emitter profiles. This process results in reduced gridline contact resistance, an undamaged emitter surface easily passivated by plasma-nitride, and a less heavily doped emitter between gridlines for reduced emitter recombination. It allows for heavier doping beneath the gridlines for even lower contact resistance, reduced contact recombination, and better bulk defect gettering. Future work in this area will incorporate the heavier emitter doping as well as performing the bulk hydrogenation before the RIE step so that surface damage from the bulk passivation step can be removed or reduced. This will be compared with the use of a protective nitride film before hydrogenation. Finally, all three plasma processes, the bulk passivation, emitter etchback, and nitride surface passivation, will be combined for the synergistic additive effect of their benefits. 


\section{Acknowledgements}

The authors would like to thank J. M. Gee for initially suggesting the self-aligned emitter etchback concept, and W. K. Schubert for his help in this area. We are also grateful to the processing staff at Sandia's PDFL and the Solarex production line for the cell processing. Many thanks also go to L. Irwin for the cell measurements.

\section{References}

[1] Z. Chen, P. Sana, J. Salami, and A. Rohatgi, "A Novel and Effective PECVD SiO2/SiN Antireflection Coating for Si Solar Cells," IEEE Trans. Elect. Dev., 40, June 1993, pp. 11611165 .

[2] D.S. Ruby, W.L. Wilbanks, C.B. Fleddermann, and J.I. Hanoka, "The Effect of HydrogenPlasma and PECVD-Nitride Deposition on Bulk and Surface Passivation in String-Ribbon Silicon Solar Cells," Proc. 13th EPSEC, October 1995, pp. 1412-1414.

[3] A. Blakers et al., "22.8\%-Efficient Silicon Solar Cell," Appl. Phys. Lett. 55, 1989, pp. 1363-1395.

[4] J. Coppye et al., "Non-Conventional Emitters for Polycrystalline Silicon Solar Cells," Proc. $10^{\text {th }}$ EPSEC, April 1991, pp. 657-660.

[5] N. Mardesich, "Solar Cell Efficiency Enhancement by Junction Etching and Conductive AR Coating Processes," Proc. 15 $5^{\text {th }}$ PVSC; May 1981, pp. 446-449.

[6] D.S. Ruby, W.L. Wilbanks, and C.B. Fleddermann, "A Statistical Analysis of the Effect of PECVD Deposition Parameters on Surface and Bulk Recombination in Silicon Solar Cells," Proc. $1^{\text {st }}$ WCPEC, Dec. 1994, pp. 1335-1338.

[7] S.R. Wenham, M.R. Willison, S. Narayanan, and M.A. Green, "Efficiency Improvement in Screen-Printed Polycrystalline Silicon Solar Cells by Plasma Treatments," Proc. $18^{\text {th }}$ PVSC, Oct. 1985, pp. 1008-1013. 